\title{
How to Mitigate the Harm of Abusive Supervision to Employee's Innovative Behaviors: The Role of Employee's Proactive Personality and Supervisor's Performance Goal Orientation
}

\author{
Jiarong She \\ School of Management, Jinan University, Guangzhou, China \\ Email: jiarong_she@163.com
}

How to cite this paper: She, J.R. (2020) How to Mitigate the Harm of Abusive Supervision to Employee's Innovative Behaviors: The Role of Employee's Proactive Personality and Supervisor's Performance Goal Orientation. Journal of Service Science and Management, 13, 45-60.

https://doi.org/10.4236/jssm.2020.131004

Received: December 20, 2019

Accepted: January 19, 2020

Published: January 22, 2020

Copyright $\odot 2020$ by author(s) and Scientific Research Publishing Inc. This work is licensed under the Creative Commons Attribution International License (CC BY 4.0).

http://creativecommons.org/licenses/by/4.0/

\section{Open Access}

\begin{abstract}
The survival and development of enterprises are increasingly dependent on individual innovative behavior. A large number of studies have shown that abusive supervision has a negligible negative impact on employee's innovative behavior. This article examines the mitigation effect of employee's proactive personality and supervisor's performance gold orientation on the relationship between abusive supervision and employee's innovative behavior. Through a paired study of 39 supervisors and 203 subordinates, a hierarchical linear model was used for analysis. The research results show that: when employees have a high proactive personality, regardless of the level of supervisor's abusive supervision, employee's innovation behavior is not affected; and when employee's proactive personality is low, the supervisor's high-performance gold orientation can mitigate the harm of abusive supervision to employee's innovative behavior.
\end{abstract}

\section{Keywords}

Abusive Supervision, Innovative Behavior, Proactive Personality, Performance Gold Orientation

\section{Introduction}

Under the new normal, the development environment of enterprises is complex and changeable, and innovation has become the key to the survival and development of enterprises. Employees are the ultimate implementers of innovation. 
Employees' innovative behavior directly affects the performance of the enterprise and plays a very important role in the development of the enterprise. Individual innovative behavior refers to the process of employees starting from identifying problems to generating innovative ideas or solutions, seeking support for their innovative ideas, putting them into practice, and finally forming products or services that can be promoted in large quantities [1]. Unlike other routine work, innovative behavior is highly risky and uncertain. Therefore, in the actual work, there are many factors that can easily inhibit or stifle the employee's innovative behavior, which makes the company miss opportunities and even cause serious consequences.

Leadership, as the most important component of the work environment, has a lot of opportunities to contact and communicate with employees during work. A large number of studies have shown that leader's management methods and behaviors can have an important impact on employees' self-efficacy and behaviors. In our country, due to the influence of traditional culture and thinking, a large number of abusive supervisions have spawned. Abusive supervision refers to the subordinates' perceptions of their supervisors' sustained display of hostile nonphysical behaviors toward them, such as ridiculing, belittling, or yelling [2]. A large number of studies at home and abroad have shown that abusive supervision will have a very serious negative impact on employee's psychology, attitudes, behaviors, etc., and will reduce employee's innovative motivation, innovative self-efficacy and innovative behavior. As a negative source of stress, abusive supervision requires employees to consume more resources to cope, so they cannot invest more resources in innovative activities; On the other hand, long-term abusive supervision will make employees question their work ability, work meaning, thus losing the enthusiasm and motivation for innovation [3]. Therefore, how to mitigate the harm of abusive supervision to employees' innovative behaviors is an issue of great concern to both the theoretical and practical circles.

The factors in the existing literature about mitigating the harm of abusive supervision to employee's innovation are roughly divided into two categories: employee's personal factors and interactions between employees and leaders or organizations. In terms of employee's personal factors, positive personal characteristics such as core self-evaluation [4] and initiative personality are helpful to alleviate the negative impact of abusive supervision on employee's innovation. Research by Liu et al. (2012) also shows that attribution motivation of team members eases the negative relationship between team leader's abusive supervision and team member's innovation: when team members interpret the abusive supervision as improving performance, this negative relationship is weak [5]. Secondly, in terms of interactions between employees and leaders or organizations, interdependence between leaders and members [6]; high level of leadership member exchange (LMX) can also mitigate the adverse effects of abusive supervision on employee's innovation. In addition, research by Wang and Tang (2015) shows that, organization-oriented employment relationships can also sig- 
nificantly reduce this negative effect. The creative interaction theory proposed by Woodman, Sawyer and Griffin (1993) holds that innovation is the result of a combination of individual and environmental factors [7]. Therefore, this paper believes that integrating the personal and environmental factors is conducive to make up for or enhance the role of a single factor, and can more comprehensively alleviate the harm of abusive supervision to employees' innovative behavior.

As the direct issuer of innovation behavior, employees' personality characteristics have a more direct and significant impact on innovation behavior. A large number of studies show that innovation as a typical proactive behavior is largely affected by the employee's proactive personality [8] [9]. Employees with a highly proactive personality usually have a proactive response to the environment. They focus on finding problems and finding opportunities, have a positive effect on generating new ideas or solutions, and then show more innovative behavior. Therefore, the highly proactive personality of employees is conducive to mitigating the negative impact of abusive supervision on their innovative behavior.

But employees have individual differences, Employees with low proactive personality tend to be content with the status and react passively to the environment. It is difficult to find problems and propose innovative ideas. They also show more negative emotions when encountering difficulties or being hit. Therefore, when such employees encounter abusive supervision, their innovative behavior will be more seriously affected. This article argues that supervisor's performance goal orientation can help low-proactive employees mitigate the adverse effects of abusive supervision. In work, the goal orientation of the supervisor directly affects his attitude and behavior, and then affects the attitude and behavior of his subordinates. Leadership with high-performance goal orientation tends to prove to others that they own or the team's ability, and they care very much about whether they can achieve better performance than other teams [10]. Therefore, they pay more attention to the performance of employees, attach importance to their thoughts and behaviors, and provide a lot of support and assistance to employees. This not only brings a certain amount of performance pressure to low-proactive employees, stimulates employee's innovation initiative, but also creates objective conditions for employee's innovation. In addition, high-performance-goal-oriented leaders often have clear performance goals. In order to meet the needs of leaders, employees often try to show their various skills and ideas, which objectively promotes the team members' innovative behavior. Therefore, for employees with low proactive personality, the supervisor's performance goal orientation can effectively alleviate the impact of abusive supervision on its innovative behavior.

Based on this, this article explores the interactive effects of abusive supervision, employee's proactive personality and supervisor's performance goal orientation on employee's innovation. The research framework of this paper is shown in Figure 1: Abusive supervision will be negatively related to employee's innovative behaviors; Employee's proactive personality will moderate the negative 


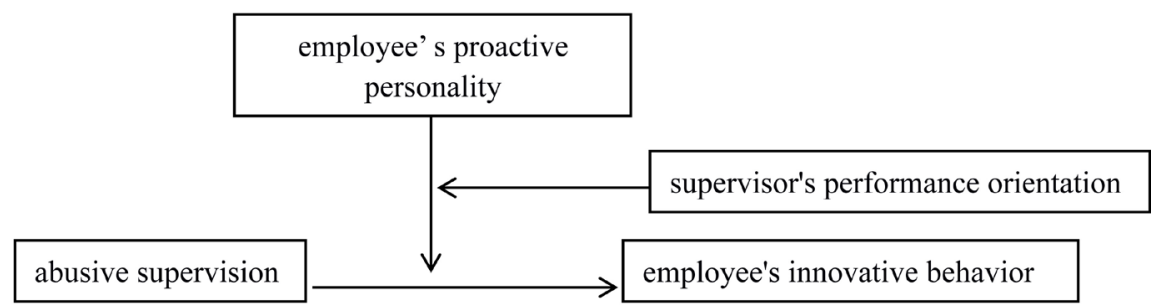

Figure 1. Research model.

relationship between abusive supervision and employee's innovative behaviors; abusive supervision, supervisors' performance goal orientation, and employee's proactive personality interaction affect employee's innovative behaviors.

\section{Theory and Hypothesis Development}

\subsection{Abusive Supervision and Employee's Innovative Behavior}

In work, because leadership determines to a large extent employees' work resource allocation, assessment, rewards, and punishments, the style and behavior of leaders play a very important role in employee's behaviors. Employee's innovative behavior refers to the process of employees starting from identifying problems to generating innovative ideas or solutions, seeking support for their own innovative ideas, putting them into practice, and finally forming products or services that can be promoted in large numbers [1]. Innovation has certain risks and uncertainties, so negative factors have a stronger impact on employees during the innovation process. Abusive supervision is a common destructive leadership behavior, which is mainly manifested by leader's persistent performance of hostile verbal and non-verbal behaviors that do not include physical contact [2]. Such as criticizing and abusing subordinates in public, ignoring subordinates, mocking subordinates, etc. Previous research has found that abusive supervision can affect employee's motivation and self-efficacy for innovation, and thus have a very negative impact on employee's innovation behaviors. From the perspective of stress, abusive supervision is a source of stress that can't be ignored for employees [11]. It will cause employees to have negative emotions such as anxiety, depression. And it will reduce the job satisfaction of employees [12], which makes employees reluctant to engage in more risky work, including new ideas and suggestions for the organization. From the perspective of resource conservation, employee's innovative behavior requires a lot of time, energy and other resources. However, because individuals have limited resources [13], when suffering from abusive supervision, employees need to consume more resources to deal with negative emotions such as anxiety and depression, so they will choose a relatively conservative way of working to reduce themselves resource consumption. From the perspective of motivation, innovative behavior is not constrained, and it mainly depends on employee autonomy. It is difficult to achieve this behavior without strong internal motivation, and long-term abusive supervision will make employees question their ability and significance [3], the- 
reby reducing enthusiasm and interest in work or organization, making employees unwilling or difficult to generate innovative ideas and behaviors about work or organization.

In summary, this study proposes the following hypotheses:

Hypothesis 1: Abusive supervision will be negatively related to employee's innovative behaviors.

\subsection{Employee's Proactive Personality and Employee's Innovative Behaviors}

In organizations, innovative behaviors usually have high risks and uncertainties. Whether or not employees make innovative behaviors is often not subject to external constraints, but more dependent on employee's personal factors, such as motivation and personality. Bateman and Crant (1993) proposed the concept of proactive personality and defined it as a relatively stable personality trait in which individuals are not subject to environmental resistance and take the initiative to change the environment [16]. Individuals with proactive personality often take the initiative to challenge the current situation, actively improve the current situation, or create a new environment. Previous research shows that proactive personality has a significant positive correlation with individual innovation [8] [9]. First of all, employees with a highly proactive personality usually have a proactive response to the environment. They are good at finding problems and looking for opportunities. At the same time, they tend to take proactive actions and have a positive effect on generating new ideas or solutions, thus showing more innovative behaviors. Secondly, the higher the proactive personality of employees, the higher the learning goal orientation, so they will continue to actively learn relevant skills and new knowledge, work harder to propose new ideas, and then show more innovative behaviors. In addition, highly proactive employees are willing to actively communicate and exchange information with team leaders or members, and use this to build a strong trust and support relationship in order to receive support and help in realizing their ideas, which is beneficial to them to do more innovative behaviors [8]. According to the review, highly proactive employees are more likely to show more innovative behaviors.

Hypothesis 2: Employee's proactive personality will be positively related to their innovative behaviors.

\subsection{The Moderating Effect of Employee's Proactive Personality}

The creative interaction theory proposed by Woodman, Sawyer and Griffin (1993) holds that innovation is an individual-level phenomenon, but this phenomenon is the result of the combined effect of individual factors and environmental factors [7]. The theory clearly emphasizes the importance of human-environment interaction for innovation. While abusive supervision affects employee's innovative behaviors, individual factors of employees also play a role [14] [15]. Innovation itself has a certain degree of difficulty and autonomy, and 
the behaviors and attitudes employees exhibit when facing such work are, to a certain extent, dominated by their proactive personality. Therefore, this paper believes that the proactive personality of employees will play a mitigating role between abusive supervision and their innovative behaviors. Faced with negative impacts such as abusive supervision, compared with employees with low proactive personality, employees with high proactive personality are less susceptible to environmental external forces and less likely to have negative emotions. They focus on finding problems and suggesting solutions, so the negative impact of abusive supervision is not obvious, and innovation behaviors will not decrease significantly. Conversely, employees with low-proactive personality are not good at identifying problems and have weak behavioral intentions. As a result, they have difficulty changing the adverse environment or coping with work pressure, and tend to negatively adapt and tolerate the current environment [16] [17]. Therefore, when they are subject to questioning or abusive supervision, they are likely to have negative emotions, which will further reduce high-risk innovative behaviors.

Based on the above analysis, this study proposes the following hypotheses:

Hypothesis 3: Employee's proactive personality will moderate the negative relationship between abusive supervision and employee's innovative behaviors such that the relationship will be weaker for individuals with a higher level of proactive personality.

\subsection{The Role of Supervisors' Performance Goal Orientation}

Employees have individual differences, and employees with low proactive personality will show more negative emotions when encountering difficulties or being hit. Therefore, when such employees encounter abusive supervision, their innovative behaviors will be more seriously affected. This study believes that for this people, certain external pressures or stimuli are needed to stimulate their innovation motivation. The supervisor's performance goal orientation can help such employees to alleviate the harm of abusive supervision. In the workplace, the supervisor's achievement goal orientation [18] is directly related to the way he is supervised and affects the attitudes and behaviors of his subordinates by affecting his own attitudes and behaviors. Supervisor with high-performance goal orientation tend to prove to others that their own or the team's ability, and they are very concerned about whether they can achieve better performance than other teams [10]. Therefore, they are willing to invest a lot of time and energy in work, pay attention to the performance of team members and the realization of short-term goals of the team, attach importance to the ideas and behaviors of employees, and provide a lot of support and help to employees to obtain better performance. This not only brings a certain amount of performance pressure to employees with low proactive personality, but the attention and support of leaders also helps to improve the internal motivation of employees, stimulates the employee's innovation enthusiasm, and thus promotes employee's innovative behaviors [19] [20]. In addition, supervisor with high-performance goal orienta- 
tion usually have clear performance goals. In order to meet the needs of supervisor's performance goal, employees often show their various skills and ideas in the team as much as possible, which objectively promotes employee's innovative behaviors. Therefore, for employees with low proactive personality, the supervisor's performance goal orientation can effectively alleviate the impact of abusive supervision on employee's innovative behaviors.

Based on this, this study believes that abusive supervision, employee's proactive personality, and supervisor's performance-goal-oriented interaction affect employee's innovative behaviors. When employees have a high proactive personality, their innovative behaviors are not affected by the level of supervisor's abusive supervision, that is, the employee's high proactive personality can effectively alleviate the harm of abusive supervision to employee's innovative behaviors; And when the employee's proactive personality is low, the supervisor's performance goal orientation will directly affect the relationship between abusive supervision and employee's innovative behavior: Supervisors are high-performance goal oriented, which brings a certain amount of pressure to employees to a certain extent, and promotes employees to show certain innovative behaviors, thereby mitigating the harm of abusive supervision to innovative behaviors.

In summary, this study proposes the following hypotheses:

Hypothesis 4: Abusive supervision, supervisors' performance goal orientation, and employee's proactive personality interaction affect employee's innovative behaviors.

\section{Methods}

\subsection{Participants and Procedures}

Data for this study came from 211 employees and their 40 immediate supervisors in a large manufacturing company in Guangdong. These participants work in teams with no less than three people in each team and have a common leader. More importantly, innovation is very important to their work. The data collection was completed in cooperation with the company's human resources department. First, the leaders and subordinates of each team are numbered, and the corresponding numbered questionnaires are sent to all the subjects by email. After the test paper is filled in, it will be sent back to the human resources department by email. Supervisors were given a questionnaire that assessed their performance goal orientation and their personal information. Direct reports were asked to rate their immediate supervisor's abusive leadership behavior, their own innovative behaviors, proactive personality and provide personal information. Since the questionnaire involved negative supervisory behavior, we assured participants that their responses would not be available to their supervisors or companies.

After excluding invalid data, 39 valid supervisor questionnaires remained, with an effective rate of 97.5\%; 203 remaining valid subordinate questionnaires, the effective rate was $95.3 \%$. In this sample structure, the majority are male 
(74.4\% are male supervisors and $78.8 \%$ are male subordinates); in terms of age distribution, the leaders are mainly 36 - 40 years old (25.6\%), and the subordinates are mainly under 35 years old (95.1\%); education is mainly concentrated in undergraduate.

\subsection{Measures}

Because Chinese is the native language of all respondents, all items were translated from English to Chinese using the back-translation approach suggested by Brislin (1980).

\subsubsection{Abusive Supervision}

We use Tepper's (2000) 15-items questionnaire [2] to measure abusive supervision. Each item starts with "My boss ...", including: "Ridicules me", "Tells me my thoughts or feelings are stupid" and so on. The instrument uses 5-point scale, 1 for never, and 5 for always. The Cronbach's alpha coefficient was 0.90 in this study.

\subsubsection{Employee's Innovative Behaviors}

We use a questionnaire developed by Scott et al. (1994) to measure employee's innovative behaviors [1]. There are 6 items. Sample items were, "I always seek to apply new processes, technologies and methods", "I often come up with creative ideas and ideas" and so on. The instrument uses a 5-point scale, 1 being very non-conforming, and 5 being very consistent. The Cronbach's alpha coefficient was 0.92 in this study.

\subsubsection{Employee's Proactive Personality}

We use a questionnaire developed by Seibert et al. (1999) to measure employee's proactive personality [21]. There are 10 items. Sample items were, "No matter where I am, I can actively change the surrounding environment", "I am always looking for better solutions to problems "and so on. The scale uses a 5-point scale, 1 being very non-conforming, and 5 being very consistent. The Cronbach's alpha coefficient was 0.76 in this study.

\subsubsection{Supervisors' Performance Goal Orientation}

We use Baraniak's (2007) performance approach orientation subscale of the work area achievement target scale [22] to measure supervisors' performance goal orientation. There are 5 items, including: "I prefer tasks that can do well and can prove my ability", "I try to find a way to prove my ability to others at work." The scale uses a 6-point scale, with 1 being very non-conforming and 6 being very consistent. The Cronbach's alpha coefficient was 0.70 in this study.

\subsection{Analysis Procedures and Strategy}

First, due to the limited time and resources of this study, all variables are self-evaluated, and there may be common method bias. Although methods such as anonymous answers and lie-tests were used to control the test, in order to 
prevent deviations from affecting the research results, Harman's single factor analysis was used to test them before data analysis. Next, following Anderson and Gerbing's (1988) recommendations, we conducted a series of CFAs to examine whether these variables captured distinct constructs. Because our variables of this study spanning both the individual level (e.g., employee's proactive personality) and group level (e.g., abusive supervision), we use Hierarchical Linear Model (HLM) to analyses our data. Our HLM analyses were composed of multiple steps. In Step 1, we entered abusive supervision. In Step 2, we entered employee's proactive personality. In Step 3 we entered the two-way interactions. In the final step, we entered the three-way interaction.

\section{Result}

\subsection{Common Method Bias Test}

Principal component analysis was performed on 31 items of 203 subordinate questionnaires in SPSS20.0, and the results showed that the KMO was 0.873, which is suitable for factor analysis; A total of 7 factors with eigenvalues greater than 1 were extracted, and the cumulative variance explanation variance was $66.06 \%$; before the rotation, the eigenvalue of the largest common factor was 8.421 , and the variance interpretation amount was $27.17 \%$, which was less than $40 \%$ and did not exceed the cumulative explanation. Therefore, there is no serious common method bias in this study.

\subsection{Confirmatory Factor Analysis}

With the exception of supervisor's performance goal orientation, the measures of abusive supervision, employee's innovative behaviors, and employee's proactive personality were all collected from the same source (employees). Therefore, following Anderson and Gerbing's (1988) recommendations, we conducted a series of CFAs to examine whether these variables captured distinct constructs.

The results are shown in Table 1 . As shown, our results suggest that the hypothesized three-factor measurement model fit the data well $\left(\chi^{2}=1054.35\right.$, RMSEA $=0.09$, NNFI $=0.93$, CFI $=0.93$ ), and better than the alternative models. These results provided support for the discriminant validity of our measures.

\subsection{Descriptive Statistics}

Table 2 shows the means, standard deviations, and intercorrelations among the

Table 1. The results of CFA.

\begin{tabular}{cccccccc}
\hline Model & $\chi^{2}$ & $\Delta \chi^{2}$ & $d f$ & $\Delta \chi^{2} / \Delta d f$ & RMSEA & NNFI & CFI \\
\hline Model 1: AS + IN + P & 4179.93 & 2993.85 & 434 & 2993.85 & 0.21 & 0.55 & 0.58 \\
Model 2: AS IN + P & 1186.08 & 131.73 & 433 & 65.87 & 0.09 & 0.91 & 0.92 \\
Model 3: AS IN P & 1054.35 & - & 431 & - & 0.09 & 0.93 & 0.93 \\
\hline
\end{tabular}

Note: AS = abusive supervision; $\mathrm{IN}=$ employee's innovative behaviors; $\mathrm{P}=$ employee's proactive personality. 
Table 2. Correlation, means, and standard deviations.

\begin{tabular}{|c|c|c|c|c|c|c|c|c|c|}
\hline & $M$ & $S D$ & 1 & 2 & 3 & 4 & 5 & 6 & 7 \\
\hline 1. Age & 31.30 & 5.67 & & & & & & & \\
\hline 2. Gender & 1.21 & 0.41 & -0.09 & & & & & & \\
\hline 3. Gender of leader & 1.21 & 0.41 & 0.02 & $0.20^{* *}$ & & & & & \\
\hline 4. Working age of leader & 2.58 & 1.00 & $0.30^{* *}$ & -0.09 & -0.08 & & & & \\
\hline 5. Education & 3.13 & 0.57 & $-0.31^{* *}$ & -0.03 & -0.05 & -0.06 & & & \\
\hline 6. Abusive supervision & 1.63 & 0.56 & 0.02 & -0.06 & 0.10 & -0.02 & $0.16^{*}$ & & \\
\hline $\begin{array}{l}\text { 7. Employees' innovative } \\
\text { behavior }\end{array}$ & 4.61 & 0.74 & 0.03 & $-0.17^{\star}$ & -0.05 & 0.07 & 0.01 & $-0.21^{\star *}$ & \\
\hline $\begin{array}{l}\text { 8. Employees' proactive } \\
\text { personality }\end{array}$ & 4.40 & 0.52 & 0.01 & -0.01 & $-0.15^{*}$ & 0.01 & -0.04 & $-0.25^{\star *}$ & $0.65^{* *}$ \\
\hline
\end{tabular}

Note: $\mathrm{N}=203,{ }^{* *} \mathrm{p}<0.01{ }^{*} \mathrm{p}<0.05$.

study variables. As can be seen in Table 2, abusive supervision related negatively to employee's innovative behaviors $(r=-0.21, \mathrm{p}<0.01)$, and related negatively to employee's proactive personality $(r=-0.25, \mathrm{p}<0.01)$. Employee's proactive personality related positively to employee's innovative behaviors $(r=0.65, \mathrm{p}<$ $0.01)$. Each variable has a significant correlation, so that is consistent with our expectations.

\subsection{Hypothetical Test}

Because our variables of this study spanning both the individual level (e.g., employee's proactive personality) and group level (e.g., abusive supervision), we use Hierarchical Linear Model (HLM) to analyses our data. Each of the cross-level hypothesized was tested with an intercepts-as-outcomes model.

All variables included in the cross terms were normalized before regression. Before conducting a formal hypothesis test, this paper conducted a zero-model test, and the results showed that for employee's innovative behaviors, the differences among groups were significant $\left(\chi^{2}=60.47, \mathrm{p}<0.05\right)$, and further analysis can be performed. Our HLM analyses were composed of multiple steps. In Step 1 we entered abusive supervision. In Step 2 we entered employee's proactive personality. In Step 3 we entered the two-way interactions. In the final step we entered the three-way interaction. Results are shown in Table 3.

Hypothesis 1 deduces that abusive supervision will significantly negatively affect employee's innovative behaviors. As we can see the model 1 in Table 3, there is a significant negative correlation between abusive supervision and employee's innovative behaviors $(\gamma=-0.15, \mathrm{p}<0.001)$. Hypothesis 1 is supported.

Hypothesis 2 deduces that the employee's proactive personality will significantly positively affect the employee's innovative behaviors. The results are shown model 2 in Table 3 . There is a significant positive correlation between employee's proactive personality and employee's innovative behaviors $(\gamma=0.49$, $\mathrm{p}<0.001)$. Hypothesis 2 is supported. 
Table 3. HLM results for hypotheses.

\begin{tabular}{|c|c|c|c|c|}
\hline \multirow{2}{*}{ Variable } & \multicolumn{4}{|c|}{ Employees' innovative behavior } \\
\hline & M1 & M2 & M3 & M4 \\
\hline \multicolumn{5}{|l|}{ Step 1} \\
\hline Intercept & $4.60^{\star * \star}$ & & & \\
\hline Abusive supervision & $-0.15^{\star * *}$ & & & \\
\hline $\mathrm{R} 2$ & $0.12^{* *}$ & & & \\
\hline \multicolumn{5}{|l|}{ Step 2} \\
\hline Intercept & & $4.60^{\star * *}$ & & \\
\hline Employee's proactive personality & & $0.49^{* * *}$ & & \\
\hline $\mathrm{R} 2$ & & $0.18^{* * *}$ & & \\
\hline \multicolumn{5}{|l|}{ Step 3} \\
\hline Intercept & & & $4.60^{* * *}$ & \\
\hline Abusive supervision (A) & & & -0.02 & \\
\hline Employee's proactive personality (B) & & & $0.48^{* * *}$ & \\
\hline $\mathrm{A} \times \mathrm{B}$ & & & 0.01 & \\
\hline $\mathrm{R} 2$ & & & $0.15^{\star * *}$ & \\
\hline \multicolumn{5}{|l|}{ Step 4} \\
\hline Intercept & & & & $4.60^{* * *}$ \\
\hline Abusive supervision (A) & & & & -0.01 \\
\hline Employee's proactive personality (B) & & & & $0.49^{* * *}$ \\
\hline Manager's performance orientation (C) & & & & $-0.11^{\star}$ \\
\hline $\mathrm{A} \times \mathrm{B}$ & & & & $0.12^{*}$ \\
\hline $\mathrm{A} \times \mathrm{C}$ & & & & -0.01 \\
\hline $\mathrm{B} \times \mathrm{C}$ & & & & 0.12 \\
\hline $\mathrm{A} \times \mathrm{B} \times \mathrm{C}$ & & & & $-0.12^{\star}$ \\
\hline $\mathrm{R} 2$ & & & & $0.17^{\star *}$ \\
\hline
\end{tabular}

Note: $\mathrm{N}_{\text {employee }}=203, \mathrm{~N}_{\text {leader }}=39 ;{ }^{*} \mathrm{p}<0.05,{ }^{* *} \mathrm{p}<0.01,{ }^{* * *} \mathrm{p}<0.001$.

Hypothesis 3 predicts that the interaction between abusive supervision and employee's proactive personality affects employee's innovative behaviors. The results are shown in model 3. The interaction terms have no significant effect on employee's innovative behaviors ( $\gamma=0.01, \mathrm{~ns})$. Hypothesis 3 is not supported. It can be seen that when the employee's proactive personality and abusive supervision are put into the equation to predict the employee's innovative behaviors at the same time, the coefficient of abusive supervision becomes insignificant, and the employee's proactive personality still has a significant impact. This means that no matter whether the abusive supervision is high or low, the employee's proactive personality has a significant predictive effect on employee's innovative behaviors. 
Hypothesis 4 predicts that the interaction between abusive supervision, manager's performance goal orientation, and employee's initiative personality will affect employee's innovative behaviors. The results are shown in model 4 . The interaction term has a significant impact on employee's innovative behaviors. The three-way interaction was significant $(\gamma=0.12, \mathrm{p}<0.05)$.

In order to clearly show the mode of moderator, a simple slope analysis was performed in this study [23] [24] [25], and the results are shown in Figure 2. When the employee's proactive personality is high and the manager's performance orientation is high, the relationship between abusive supervision and employee's innovative behavior is not significant ( $\gamma=0.0014$, ns); When the employee's proactive personality is high and the manager's performance orientation is low, the relationship between abusive supervision and employee's innovation behavior is not significant ( $\gamma=-0.0039, \mathrm{~ns})$; when employee's proactive personality is low and manager's performance goal orientation is high, there is a significant positive correlation between abusive supervision and employee's innovative behavior ( $\gamma=0.15, \mathrm{P}<0.05$ ); when the employee's proactive personality is low and manager's performance goal orientation is low, there is a significant negative correlation between abusive supervision and employee's innovative behaviors $(\gamma=-0.15, \mathrm{p}<0.05)$.

In conclusion, the research model of this paper is established, and the four hypotheses are verified. In other words, we have proved that, abusive supervision will be negatively related to employee's innovative behaviors; employee's proactive personality will moderate the negative relationship between abusive supervision and employee's innovative behaviors; abusive supervision, supervisors' performance goal orientation, and employee's proactive personality interaction affect employee's innovative behaviors.

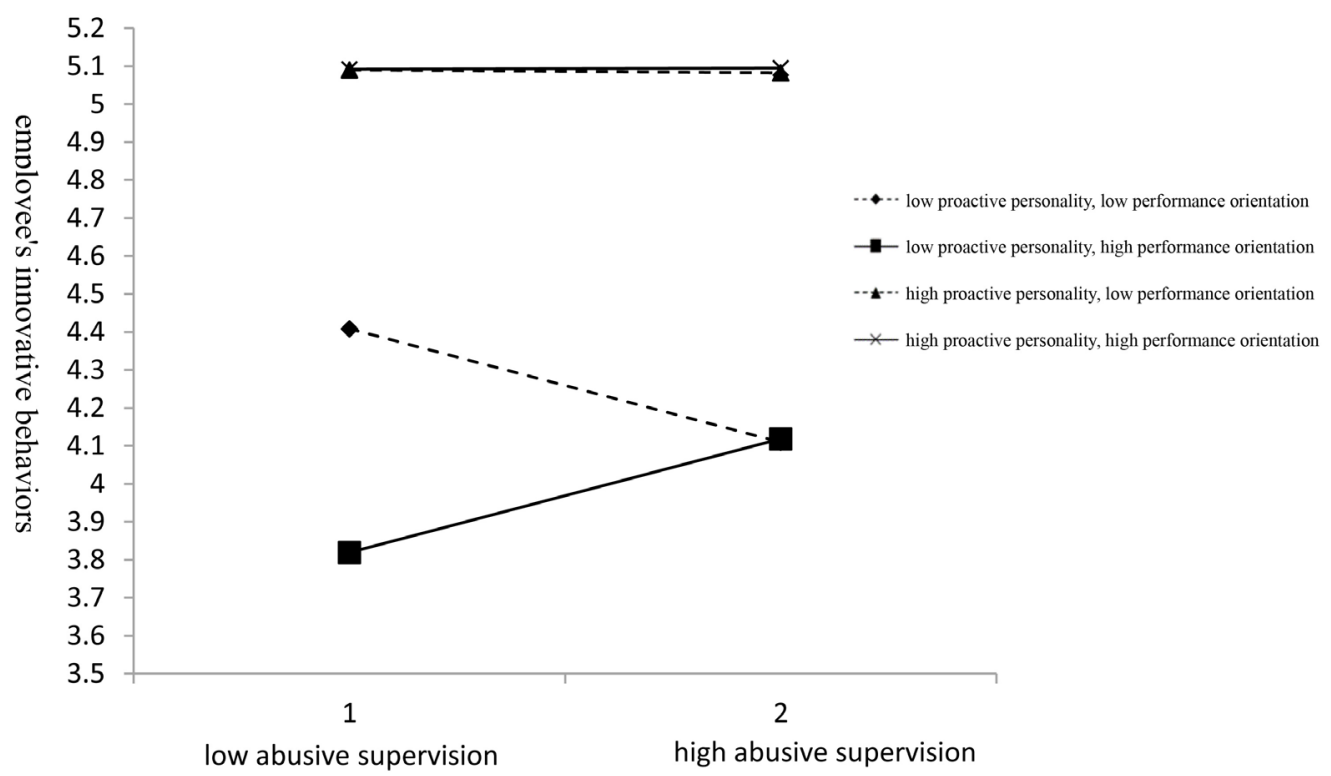

Figure 2. Moderating effect of abusive supervision, employee's proactive personality and manager's performance orientation. 


\section{Conclusion}

Innovation is not only an important source for an organization to gain a competitive advantage, but also one of the most effective ways for an organization to respond to a changing environment. But innovation means various risks and uncertainties. King et al. (1992) pointed out that the realization of organizational innovation must ultimately be implemented to employees in the organization, and the employee's innovative behaviors are the core element of organizational innovation [26]. Abusive supervision is widespread and has a serious impact on employee's innovation. How to mitigate the harm of abusive supervision to employee's innovative behaviors is one of the most important issues for organizational development. The creative interaction theory proposed by Woodman et al. believes that innovation is the result of the combined effect of individual factors and environmental factors [6]. Therefore, this study explores the interactive effects of abusive supervision, supervisor's performance goal orientation, and employee's proactive personality on employee's innovative behaviors, and conducts empirical research with 39 grassroots teams in a manufacturing company in Guangdong as the research object. The results show that when the employee's proactive personality is high, the employee's innovative behaviors are not affected by abusive supervision; and when the employee's initiative personality is low, the high-performance goal orientation of supervisors can mitigate the negative impact of abusive supervision on employee's innovation. This research has produced some interesting theoretical and managerial implications.

\subsection{Theoretical Implication}

First, this study improves understanding of the relationship between abusive supervision and employee's innovation. Previous researches on abusive supervision and employee's innovation have focused on exploring their possible impact mechanisms. This study, from the perspective of how to mitigate the harm of abusive supervision, uses paired data to explore the impact of the interaction of employee's individual factors (employee's proactive personality) and environmental factors (supervisor's performance goal orientation) on employee's innovative behaviors. It has been proved that the employee's proactive personality and supervisor's performance goal orientation can effectively alleviate the adverse impact of abusive supervision on employee's innovative behaviors.

Second, although our model specifically addresses the adverse effects of abusive supervision on employee's innovation, its core may apply to victims of various types of interpersonal abuse. Research by Tepper et al. (2011) reveals overlap between various constructs related to interpersonal abuse, such as bullying, uncivilization and social isolation [27]. These constructs are related to interpersonal abuse, and various types of interpersonal abuse at work may represent an adverse environment that undermines innovation. Future research can use our framework to study how to mitigate the adverse effects of these environments. 


\subsection{Managerial Implications}

In China, under the influence of traditional cultural atmosphere such as high-power distance, abusive supervision can easily breed in the workplace, which in turn has a great negative impact on the development of employees and organizations. This study provides the following implications for how to mitigate the harm of abusive supervision:

First of all, companies should control the selection of leaders, establish corresponding systems and measures, incorporate ethical behaviors into the assessment system, and restrict and punish negative behaviors such as abusive supervision of leaders, so that members of the organization can be treated with respect and fairness; at the same time, the organization should strengthen the training of supervisors, improve their management literacy, transmit positive supervisor behavior, and change or reduce the occurrence of abusive supervision.

Second, research shows that managers' emotions and stress are related to abusive supervision [28]. Therefore, managers must find other ways to release their work stress and negative emotions, rather than abusing subordinates. At the same time, managers should be performance-goal-oriented in their work, so that employees can work closely around certain work goals or performance, so as to reduce the impact of other adverse factors in the work.

Finally, in the process of talent development and training, companies should focus on the proactive personality of employees. When recruiting, companies can use mature proactive personality scales to screen employees with highly active personality; for employees with low-active personality, companies should use the corresponding internal management mechanisms (such as promotion and salary adjustment) to enhance the corporate performance-oriented atmosphere and stimulate employee's initiative awareness and behaviors.

\subsection{Limitations}

First, our measurement of abusive supervision is based only on frequency. Although this method is consistent with most previous studies, the frequency and intensity of abusive supervision may have different effects. For example, although loud abusiveness and disregard are both considered abusive supervision, their impact on employee's innovation is not exactly the same. Therefore, future research can consider $2 \times 2$ abusive supervision research including high/low frequency and high/low intensity.

Second, our research only examines the impact and mitigation of abusive supervision at the individual level on employees' individual innovative behaviors, and the abusive supervision at the team level is likely to hinder team creativity. In order to enrich the theory and knowledge of abusive supervision and creativity at the team level, future research can examine how team-level abusive supervision affects team creativity and how to mitigate such team-level effects.

Finally, this study uses subjective self-assessment to measure variables. The 
analysis results may be affected by common method bias. Future research can use a combination of self-assessment and other assessments to improve the validity of the measurement.

\section{Conflicts of Interest}

The authors declare no conflicts of interest regarding the publication of this paper.

\section{References}

[1] Bruce, S.R.A. (1994) Determinants of Innovative Behavior: A Path Model of Individual Innovation in the Workplace. The Academy of Management Journal, 37, 580-607. https://doi.org/10.2307/256701

[2] Tepper, B.J. (2000) Consequences of Abusive Supervision. The Academy of Management Journal, 43, 178-190. https://doi.org/10.2307/1556375

[3] Rafferty, A.E. and Restubog, S.L.D. (2011) The Influence of Abusive Supervisors on Followers. Organizational Citizenship Behaviours: The Hidden Costs of Abusive Supervision. British Journal of Management, 22, 270-285. https://doi.org/10.1111/j.1467-8551.2010.00732.x

[4] Zhang, H., Kwan, H.K., Zhang, X., et al. (2014) High Core Self-Evaluators Maintain Creativity: A Motivational Model of Abusive Supervision. Journal of Management, 40, 1151-1174. https://doi.org/10.1177/0149206312460681

[5] Liu, D., Liao, H. and Loi, R. (2012) The Dark Side of Leadership: A Three-Level Investigation of the Cascading Effect of Abusive Supervision on Employee Creativity. Academy of Management Journal, 55, 1187-1212. https://doi.org/10.5465/amj.2010.0400

[6] Rousseau, V. and Caroline, A. (2018) When Leaders Stifle Innovation in Work Teams: The Role of Abusive Supervision. Journal of Business Ethics, 151, 651-664. https://doi.org/10.1007/s10551-016-3258-8

[7] Woodman, R.W., Sawyer, J.E. and Griffin, R.W. (1993) Toward a Theory of Organizational Creativity. Academy of Management Review, 18, 293-321. https://doi.org/10.5465/amr.1993.3997517

[8] Seibert, S.E., Kraimer, M.L. and Crant, J.M. (2006) What Do Proactive People Do? A Longitudinal Model Linking Proactive Personality and Career Success. Personnel Psychology, 54, 845-874. https://doi.org/10.1111/j.1744-6570.2001.tb00234.x

[9] Gong, Y., Cheung, S.Y., Wang, M., et al. (2012) Unfolding the Proactive Process for Creativity: Integration of the Employee Proactivity, Information Exchange, and Psychological Safety Perspectives. Journal of Management, 36, 603-612. https://doi.org/10.1177/0149206310380250

[10] Vandewalle, D. (1997) Development and Validation of a Work Domain Goal Orientation Instrument. Educational and Psychological Measurement, 57, 995-1015. https://doi.org/10.1177/0013164497057006009

[11] Nandkeolyar, A.K., Shaffer, J.A., Li, A., et al. (2014) Surviving an Abusive Supervisor: The Joint Roles of Conscientiousness and Coping Strategies. Journal of Applied Psychology, 99, 138-150. https://doi.org/10.1037/a0034262

[12] Tepper, B.J., Moss, S.E. and Carr, L.J.C. (2007) Abusive Supervision, Upward Maintenance Communication, and Subordinates' Psychological Distress. The Academy of Management Journal, 50, 1169-1180. https://doi.org/10.2307/20159918 
[13] Hobfoll, S.E. (1989) Conservation of Resources. A New Attempt at Conceptualizing Stress. American Psychologist, 44, 513-524. https://doi.org/10.1037/0003-066X.44.3.513

[14] Amabile, T.M. (1988) A Model of Creativity and Innovation in Organizations. Research in Organizational Behavior, 10, 123-167.

[15] Amabile, T.M., Conti, R., Coon, H., et al. (1996) Assessing the Work Environment for Creativity. The Academy of Management Journal, 39, 1154-1184. https://doi.org/10.2307/256995

[16] Bateman, T.S. and Crant, J.M. (1999) Proactive Behavior: Meaning, Impact, Recommendations. Business Horizons, 42, 63-70. https://doi.org/10.2307/256995

[17] Parker, S.K. and Collins, C.G. (2010) Taking Stock: Integrating and Differentiating Multiple Proactive Behaviors. Journal of Management, 36, 633-662. https://doi.org/10.1177/0149206308321554

[18] Dweck, C. and Leggett, E. (1988) A Social-Cognitive Approach to Motivation and Personality. Psychological Review, 95, 256-273. https://doi.org/10.1037/0033-295X.95.2.256

[19] Amabile, T.M., Schatzel, E.A., Moneta, G.B., et al. (2004) Leader Behaviors and the Work Environment for Creativity: Perceived Leader Support. Leadership Quarterly, 15, 5-32. https://doi.org/10.1016/j.leaqua.2003.12.003

[20] Janssen, O. (2005) The Joint Impact of Perceived Influence and Supervisor Supportiveness on Employee Innovative Behaviour. Journal of Occupational \& Organizational Psychology, 78, 573-579. https://doi.org/10.1348/096317905X25823

[21] Seibert, S.E., Crant, J.M. and Kraimer, M.L. (1999) Proactive Personality and Career Success. Journal of Applied Psychology, 84, 416-427. https://doi.org/10.1037/0021-9010.84.3.416

[22] Baranik, L.E., Barron, K.E. and Finney, S.J. (2007) Measuring Goal Orientation in a Work Domain: Construct Validity Evidence for the 2 x 2 Framework. Educational and Psychological Measurement, 67, 697-718.

https://doi.org/10.1177/0013164406292090

[23] Bauer, D.J. and Curran, P.J. (2005) Probing Interactions in Fixed and Multilevel Regression: Inferential and Graphical Techniques. Multivariate Behavioral Research, 40, 373-400. https://doi.org/10.1207/s15327906mbr4003_5

[24] Curran, P.J., Bauer, D.J. and Willoughby, M.T. (2006) Testing and Probing Interactions in Hierarchical Linear Growth Models.

[25] Preacher, K.J., Curran, P.J. and Bauer, D.J. (2006) Computational Tools for Probing Interactions in Multiple Linear Regression, Multilevel Modeling, and Latent Curve Analysis. Journal of Educational and Behavioral Statistics, 31, 437-448. https://doi.org/10.3102/10769986031004437

[26] King, N. (2011) Modelling the Innovation Process: An Empirical Comparison of Approaches. Journal of Occupational \& Organizational Psychology, 65, 89-100. https://doi.org/10.1111/j.2044-8325.1992.tb00487.x

[27] Tepper, B.J. and Henle, C.A. (2011) A Case for Recognizing Distinctions among Constructs That Capture Interpersonal Mistreatment in Work Organizations. Journal of Organizational Behavior, 32, 487-498. https://doi.org/10.1002/job.688

[28] Duffy, M.K., Shaw, J.D., Scott, K.L., et al. (2006) The Moderating Roles of Self-Esteem and Neuroticism in the Relationship between Group and Individual Undermining Behavior. Journal of Applied Psychology, 91, 1066-1077.

https://doi.org/10.1037/0021-9010.91.5.1066 